\title{
A condição histórico-social da mulher na perspectiva socialista: um estudo das trajetórias de Rosa Luxemburgo e Alexandra Kollontai \\ Professora da Faculdade de Ensino Superior Dom Bosco (PR)
}

\section{Resumo}

Este estudo é qualitativo-histórico-bibliográfico, pauta-se nos referenciais da análise crítico-dialética. Objetiva-se apontar as contribuições das socialistas Alexandra Kollontai e Rosa Luxemburgo para se pensar a condição da mulher na sociedade. A fundamentação téorica constitui-se especialmente ao redor do resgate historiográfico da produção matricial de Kollontai e Luxemburgo. Indaga-se: "historicamente, qual foi a contribuição das produções das mulheres socialistas, especialmente Kollontai e Luxemburgo e o que essas concepções e reflexões oferecem para a análise, a crítica e a busca da superação da condição das mulheres na sociedade de classes?" Pressupõe-se que a teoria marxista e mais especificamente o pensamento de Kollontai e Luxemburgo nos ofereceram argumentos fundamentais para se pensar a condição da mulher na sociedade, a dominação do trabalho, a divisão sexual do trabalho e a exploração sexual, que é consequência desse embate.

Palavras-chave: Mulheres socialistas; Rosa Luxemburgo; Alexandra Kollontai.

\begin{abstract}
This study is qualitative-historical-bibliographical references on the agenda of critical-dialectical analysis. It aims to point out the contributions of socialist Rosa Luxemburg and Alexandra Kollontai to think about the condition of women in society. The rationale Theoretical constitutes especially around the rescue historiographical production matrix Kollontai and Luxembourg. One wonders: "Historically, what was the contribution of the outputs of socialist women, especially Kollontai and Luxembourg and that these conceptions and reflections to offer analysis, criticism and seeks to overcome the condition of women in class society?" Assumed that Marxist theory, and more specifically the thought of Kollontai and Luxembourg offered us the fundamental arguments for thinking the condition of women in society, the domination of labor, the sexual division of labor and sexual exploitation, which is a result of this clash.
\end{abstract}

Key-words: Socialist women, Rosa Luxemburg, Alexandra Kollontai. 


\section{Introdução}

s relações entre homens e mulheres sempre foram a base da
sociabilidade humana. Desde os primeiros agrupamentos
humanos, a economia e a política da sexualidade e da reprodução estiveram na origem e na identidade de todas as produções e reproduções da vida coletiva. Distintas concepções e representações dessas relações pautaram as formações econômicas, ideológicas e políticas das sociedades humanas, presentes na mitologia, na tradição oral, na religião e nos códigos jurídicos e políticos historicamente produzidos. Desde a formação dos agrupamentos clânicos e tribais até os nossos dias, há diversidade de compreensão e de representação política desses papeis sociais e sexuais, definidos por homens e mulheres na produção material da vida. As sociedades primitivas viveram fases e etapas matriarcais, marcadamente subsumidas a partir da organização das formas primárias de ordenamento de classes ou estamentos, na origem da família patriarcal, da propriedade privada e do Estado (Engels, 1974).

Apesar dessa ancestral tensão, a compreensão da condição da mulher na sociedade nunca deixou de ser posta. A ideologia burguesa anunciaria a superação das matrizes escravistas e feudais ao conceber uma nova ordem natural e social, mas não seria capaz de realizar essa superação. O ideário socialista revolucionário, a partir das contribuições e referenciais de Marx e Engels, no século XIX, desenvolve um singular e especifico referencial para a compreensão das determinações históricas, econômicas, políticas, ideológicas e culturais, que sustentam as diferentes disposições da produção da vida entre os sexos: homens e mulheres. O movimento socialista construiu uma peculiar análise da condição econômica, ideológica e histórica da mulher na sociedade.

Considerando a importância da produção de mulheres socialistas como Kollontai e Luxemburgo, cujas produções precisam ser recuperadas, reconhecidas e ampliadas, pois a militância das mulheres socialistas representa uma luta histórica e revolucionária, um embate político para enfrentamento da desigualdade, dos abusos, violência e discriminações, da 
opressão contras as mulheres trabalhadoras nasce a necessidade e relevância inicial da realização deste estudo que buscará resgatar o papel que as mulheres socialistas, feministas, marxistas, revolucionárias que desempenharam no processo histórico da luta pela classe trabalhadora objetivando a igualdade social.

Parafraseando Toledo em sua apresentação do livro de Kollontai (2007, p. 23), acreditamos que não podemos nos contentar que a história durma nas páginas dos livros, e reconhecer o papel que estas socialistas cumpriram na luta pela mudança da situação da mulher é uma forma de acordar o que está latente e convocar as pessoas a pensarem e reconhecerem que especialmente Kollontai e Luxemburgo representam no campo feminino marxista um marco no processo revolucionário para instaurar a participação da mulherde maneira ativa em todas as instâncias da sociedade. A sexualidade humana, assim como as outras instâncias da vida, é uma construção histórica e social e, neste sentido, acreditamos que os escritos de Engels sobre a "A Origem da Família, da Propriedade e do Estado", publicado pela primeira vez em 1884 , ainda hoje apresentam as bases fundamentais para sua compreensão, sendo a família a instituição na qual reconhecemos vir a se consolidar a ideologia sexual dominante.

A forma de família que corresponde à civilização e vence definitivamente com ela é a monogamia, a supremacia do homem sobre a mulher, e a família individual como unidade econômica da sociedade. A força de coesão da sociedade civilizada é o Estado, que, em todos os períodos é exclusivamente o Estado da classe dominante e, de qualquer modo, essencialmente uma máquina destinada a reprimir a classe oprimida e explorada (Engels, F., 1974, p.140).

Embora o corpo tenha sido visto sempre como objeto servil, mão de obra para produção de capital, hoje temos uma sociedade que "coisificou" o corpo, principalmente o corpo da mulher, fruto de uma sexualidade mercantilizada pela sociedade consumista e de uma pseudolibertação da mulher. Como afirma Nunes (2003, p. 98): 
[...] o capitalismo apreendeu a sexualidade como o grande grito e a incorporou à sua máquina de consumo: toda a propaganda passa a falar de sexo, a estimular e referir-se aos anseios sexuais de nosso tempo. Até mesmo as coisas mais simples são vendidas com o distintivo do sexo. A luta da mulher é estigmatizada e a mulher é a "garota propaganda" do consumismo. Seu próprio corpo é consumido.

De acordo com Engels e Marx, o passo inicial para emancipação (e não o último) seria a incorporação da mulher no trabalho social produtivo. Engels (1974, p. 182) afirma que:

A emancipação da mulher e sua equiparação ao homem são e continuarão sendo impossíveis, enquanto ela permanecer excluída do trabalho produtivo social e confinada ao trabalho doméstico, que é um trabalho privado. A emancipação da mulher só se torna possível quando ela pode participar em grande escala, em escala social, da produção, e quando o trabalho doméstico lhe toma apenas um tempo insignificante.

Entre as muitas contradições desse movimento histórico, vivido na tensão das disputas da expansão do capital nos séculos XIX, XX e XXI permanecem vivos os documentos, debates, livros, artigos, as conquistas e os embates das militantes feministas socialistas, no bojo dos movimentos políticos que definem o cenário do socialismo revolucionário, notadamente europeu e soviético, embora haja repercussões em diferentes países e culturas coetâneas a essas idéias e embates. O presente estudo quer considerar essa realidade e retomar, a partir da produção das mulheres militantes socialistas Alexandra Kollontai e Rosa Luxemburgo, buscando recuperar a história e a historiografia socialista dos estudos e movimentos sobre a condição da mulher na sociedade contemporânea. Trata-se de retomar a questão da origem das diferenças de poder, econômico, cultural e político, entre homens e mulheres, mostrando que não é de hoje que se reconhece a luta pela igualdade social entre homens e mulheres em busca do respeito às diferenças biológicas: diferenças essas que não podem servir para subordinar e inferiorizar a mulher em todos os contextos sociais, mas que se impõem como derivações estruturais de uma sociedade 
discriminatória, que se origina da sociedade de classes e da divisão social do trabalho, a partir de uma clivagem de natureza sexual.

Considerando Toledo in Kollontai (2007, p.18) a Rússia soviética em dois meses "fez mais pela emancipação da mulher do que os mais avançados países capitalistas em todos os tempos". Ali foram abolidas todas as leis que se relacionavam às desigualdades entre homens e mulheres, como a questão da igualdade de direitos no casamento, foram criados decretos que estabeleciam a proteção para mulheres e crianças, pensão alimentícia, filhos naturais, seguro social, entre outros. Se pensarmos nos dias de hoje, também tomamos consciência de que muitas leis foram criadas nesse sentido, no entanto, é necessário ressaltar que apenas a criação de leis não garante a igualdade de fato.

A desigualdade econômica, consequentemente, é social. Foi nesse sentido que Lenin (1919) apud Toledo na apresentação do livro de Kollontai (2007, p. 20) afirmou que:

A emancipação da mulher, o comunismo verdadeiro começará quando e onde se inicie uma luta sem quartel, dirigida pelo proletariado, dono do poder do estado, contra essa natureza do trabalho doméstico, ou melhor quando se inicie sua transformação total, em uma economia de grande escala.

Historicamente a mulher sempre foi discriminada na história, reprimida, inferiorizada, por muito tempo, excluída da vida social e educativa, de sua condição de sujeito; considerada um ser frágil, passivo, que deveria ser educada apenas para exercer seu papel de mãe e esposa, atuando no seio familiar. Muitos foram os movimentos e lutas para superar essa condição culturalmente imposta. Reconhecemos muitas conquistas e demandas sobre a condição da mulher e a construção de uma nova identidade de gênero, como o direito de voto, a frequentar a escola, as mudanças no código civil como o direito ao divórcio, a Lei Maria da Penha, entre outras. Todavia, a despeito dessa realidade, com a patente mudança de algumas atávicas disposições de dominação, prevalecem culturas e movimentos dispersos, confusos, parciais e contraditórios, no tocante à 
análise da gênese e matriz das dominações de gênero. Reproduzem-se lugares comuns, sínteses frágeis e palavras de ordem estreitas, quando não banais. Não se dispõe cumulativamente da tradição crítica e da proposição política das mulheres e dos movimentos socialistas.

Esse é o escopo da presente proposição de estudos: recuperar a grade conceitual, política, ética e estética da historiografia socialista de gênero, a partir da produção matricial de militantes feministas das décadas iniciais do século passado, para confrontar com as reflexões, bandeiras e estudos que apontem as potencialidades de emancipação da mulher nos dias atuais.

\section{Metodologia e referencial teórico}

A pesquisa realizar-se-á sob a identidade e procedimentos de uma investigação como abordagem qualitativa de caráter histórico-bibliográfico tendo como suporte a literatura especializada sobre sexualidade humana, educação sexual e formação ético-política. A pesquisa fundamenta-se nos referenciais conceituais da análise crítico-dialética. Esta análise compõe a categoria epistemológica fundamental denominada de práxis (reflexão-açãoreflexão), e têm como objetivo a transformação social. Os pressupostos gnosiológicos deste paradigma centram-se na concreticidade, na relação dialética entre sujeito e objeto. Sánchez Gamboa (1987, p.103-104) esclarece que:

Nas pesquisas dialéticas, o homem é tido como ser social e histórico; embora determinado por contextos econômicos, políticos e culturais, é o criador da realidade social e o transformador desses contextos. A educação é vista como uma prática nas formações sociais e resulta de suas determinações econômicas, sociais e políticas; faz parte da superestrutura e, junto com outras instâncias culturais, atua na reprodução da ideologia dominante. Numa outra versão, a educação também é espaço da reprodução das contradições que dinamizam as mudanças e possibilitam a gestação de novas formações sociais.

Esta abordagem apresenta uma concepção de história com uma preocupação diacrônica. Considerando ainda Sánchez Gamboa (1987, p.105): 
A história como eixo da explicação e da compreensão científicas, e têm na ação uma das principais categorias epistemológicas. A ação é, na sua concretude, critério de verificação da relação cognitiva e prova da coincidência das leis do ser e do pensar. A história, na dialética, não é, como nas pesquisas empírico-analíticas, um dado acidental ou secundário. À semelhança dos exemplos anteriores, as pesquisas preocupadas com a diacronia podem ser comparadas ao cinema, pois se preocupam com o registro do movimento, a evolução e a dinâmica dos fenômenos.

A abordagem crítico-dialética compreende a realidade como um processo dinâmico e histórico, à luz do conceito de conflito, buscando a conscientização crítica e a transformação político-social. O homem é visto como agente histórico. Conforme Faria Jr (1992, p.29) “o paradigma crítico-dialético considera a ação como categoria epistemológica fundamental." Este paradigma permite elucidar as relações do "fenômeno educativo" com a sociedade e ajuda a compreender a dinâmica e as contradições da prática profissional do educador. As pesquisas críticodialéticas, na opinião de Sánchez Gamboa (1987 p. 97):

Questionam fundamentalmente a visão estática da realidade implícita nas abordagens anteriores. Esta visão esconde o caráter conflitivo, dinâmico e histórico da realidade. Sua postura marcadamente crítica expressa a pretensão de desvendar, mais que o 'conflito de interpretações', o conflito dos interesses.

O materialismo dialético será o substrato. Sobre o materialismo histórico, Frigotto (1995, p. 17) esclarece:

O pressuposto fundamental da análise materialista histórica é de que os fatos sociais não são descolados de uma materialidade objetiva e subjetiva e, portanto, a construção doconhecimento histórico implica o esforço de abstração e teorização do movimento dialético (conflitante, contraditório, mediado) da realidade.Trata-se de um esforço de ir à raiz das determinações múltiplas e diversas (nem todas igualmente importantes) que constituem determinado fenômeno. Apreender as determinações do núcleo fundamental de um fenômeno, sem o que este fenômeno não se constituiria, é o exercício 
por excelência da teorização histórica de ascender do empírico contextualizado, particularizado e, de início, para o pensamento caótico - ao concreto pensado ou conhecimento. Conhecimento que, por ser histórico e complexo e por limites do sujeito que conhece, é sempre relativo.

Mas, em que consiste seu caráter histórico? O que é História? Pode-se dizer que é o resultado do que os homens produzem através de sua vida coletiva ou individual, baseados nos mais diversos interesses, como afirmam Marx e Engels (1967, p. 159):

A História não faz nada, não possui enorme riqueza, ela não participa de nenhuma luta". Quem faz tudo isso, quem participa das lutas é o homem como meio para realizar seus fins - como se tratasse de uma pessoa individual -, pois a História não é senão a atividade do homem que persegue seus objetivos.[...]

A concepção marxista coloca o homem como o centro da história e o centro da ciência na história. Marx rompe com a visão metafísica da História. Retomando Marx e Engels (1984, p. 30):

[...] Temos que começar constatando o primeiro pressuposto de toda existência humana e portanto de toda história, a saber o pressuposto de que os homens precisam estar em condições de viver para 'fazer história'. Mas para viver é preciso antes de mais nada comer, morar, vestir, e ainda algumas coisas mais, o primeiro ato histórico é portanto engendrar os meios para satisfação dessas necessidades, produzir a vida material para a mesma, e isto é um ato histórico, uma condição básica de toda a história que ainda hoje, como há milênios, precisa ser preenchida a cada dia e a cada hora, tão somente para manter os homens vivos. [...] Em segundo lugar, a primeira necessidade satisfeita, a ação da satisfação e o instrumento da satisfação adquirida levam a novas necessidades - e esse engendramento de novas necessidades é o primeiro ato histórico [...] A terceira circunstância, o que já de antemão entra no desenvolvimento histórico, é a de que os seres humanos que renovam sua própria vida diariamente começam a fazer outros seres humanos, isto é, a reproduzirem a relação entre homem e mulher, pais e filhos, a família. [...] 
Fazer uma pesquisa histórica requer do pesquisador, retomar $\mathrm{o}$ percurso, olhar para trás, sair de si mesmo, entender que a história é composta por seres vivos, que se movem, agem, que se transformam. Portanto, a história não é estática, acabada, mas contínua e marcada por lutas, embates políticos, sociais, econômicos. Os fatos e acontecimentos passados influenciam os novos rumos que esta história irá tomar, ela é necessária para entendermos a realidade, porque a história constrói a realidade.

Sendo assim, a problemática da condição da mulher na sociedade será também localizada no contexto do desenvolvimento da História da Educação, considerando os conflitos e contradições da evolução da sociedade como um todo, e os determinantes sócio-econômicos decorrentes da formação capitalista e seus desdobramentos éticos, políticos e estéticos que influenciam as concepções de educação como um todo e da educação sexual em particular. De acordo com Nunes (1996, p.31) são estas bases da ontologia dialética marxista, superam "a linearidade, o paradigma da explicação puramente restrita, idealista, harmoniosa, distintiva, cartesiana pelas categorias da contradição, conflitos, ideologias, materialidade, mediação e concepção política". A dialética busca a superação do sensocomum, com uma visão de mundo que acentua as contradições e a dinamicidade. Acreditamos que a emancipação do homem fundamentalmente é histórica, econômica, que só irá se concretizar a partir da superação da divisão social do trabalho.

A dimensão estrutural de nosso campo investigativo constitui-se ao redor do resgate historiográfico das produções femininas socialistas para se pensar a sexualidade e o preconceito de gênero dentre os quais destacamos LUXEMBURGO e KOLLONTAI, cujas obras ou estudos sobre as mesmas serão nosso maior referencial. No Brasil nos pautaremos em NUNES, SILVA, LOURO, LOUREIRO, GOLDEMBERG, KONDER, entre outros que estudam a temática da sexualidade e de gênero. Trata-se aqui da tarefa de recompor as produções de Kollontai e Luxemburgo mostrando sua importância e determinando a circunscrição epistemológica e política desse tema nas Ciências Humanas e Sociais. 
Os estudos sobre Sexualidade, Educação, Cultura e Sociedade tiveram vertentes distintas: de um lado a trajetória empreendida a partir das concepções e pesquisas de Havelock ELLIS (1859 - 1939) e Sigmund FREUD (1856-1939) acentuando as articulações entre a biologia da sexualidade e sua dimensão subjetiva ou psíquica, alcançando notável desenvolvimento nos fins do século XIX e no transcorrer de todo o século XX. As concepções de Freud apontavam para o desvendamento dos traumas, repressões, representações morais e éticas da sexualidade na vida cotidiana, na personalidade da pessoa e nas dimensões sociais. Tratava-se de uma linha de pesquisa centrada na questão da individualidade burguesa como substrato. Freud (apud Marcuse, 1981, p.36) considerava que a história do homem é a história de sua repressão e sustentava que a repressão da sexualidade tem um motivo econômico: "como não tem meios suficientes para sustentar a vida de seus membros sem trabalho por parte deles, (a sociedade) trata de restringir o número de seus membros e desviar suas energias das atividades sexuais para o trabalho"

A linha evolucionista alcançara notável expressão com o papel da sexualidade nas teorias biológicas centradas no marco de Charles DARWIN (1809-1882) e suas inspirações no campo das Ciências Biológicas e suas aproximações. Tratava-se de uma biologia da sexualidade.

No transcorrer do século XX tivemos grande impulso para as pesquisas e estudos temáticos sobre sexualidade. Podemos reconhecer a grandiosa contribuição de autores como Eric FROMM (1900-1980), Wilhelm REICH (1897-1957) Herbert MARCUSE (1898-1979) e Michel FOUCAULT (1926-1984), para ficar nos principais representantes desse período. Por outro lado vimos avançar as pesquisas de natureza empirista ou pragmática, notadamente na sociedade burguesa americana, como podem comprovar os estudos de Wiliam MASTER's (1915-2001) \& Virginia JONHSON (1925), o conhecido Relatório KINSEY (1948) publicado por Alfred Kinsey (1894-1956) e suas derivações ou influências. Nota-se que a condição da Mulher, a abordagem e questionamento sobre sexualidade andaram a passos emparelhados nessa conjuntura. 


\section{As contribuições de Rosa Luxemburgo e Alexandra Kollantai}

Embora ainda sejam recentes as conquistas por seus direitos e a mulher ainda sofra muito preconceito e é tratada com desigualdade seja no trabalho, em casa ou na sociedade, a luta pela igualdade de gênero vem de longa data. Kollontai escreveu originalmente em 1909, no seu livro "As bases sociais da questão feminina" reproduzido em Kollontai (1982, p.13) que a emancipação da mulher vai além dos entraves econômicos, precisando superar a base moral familiar:

É óbvio que a aspiração das mulheres à igualdade de direitos não será plenamente satisfeita pela luta, pela emancipação política, a obtenção de um doutorado ou outros graus acadêmicos, ou salário igual por trabalho igual. Para tornar-se realmente livre, a mulher tem que se desembaraçar das cadeias que faz pesar sobre ela a forma atual, ultrapassada e constrangedora, da família. Para a mulher, a solução do problema familiar não é menos importante que a conquista da igualdade política e o estabelecimento de sua plena independência econômica.

Essa proposição demonstra que muitas das bandeiras, nos dias de hoje levantadas, já estavam sendo hasteadas há tempos atrás. A luta pela condição da mulher é de longa data e ainda hoje nos questionamos se esta moral familiar e social que pesava sobre a mulher foi superada. Sendo assim, partiremos da premissa que a teoria marxista e mais especificamente o pensamento das mulheres socialistas como Alexandra Kollontai(18721953) e Rosa Luxemburgo (1871-1919), nos ofereceram argumentos fundamentais para se pensar a condição da mulher na sociedade, a dominação do trabalho, que posteriormente nos ajudaram a pensar sobre a divisão sexual do trabalho e sobre a exploração sexual, que é uma conseqüência desse embate.

Rosa Luxemburgo (1871-1919) certamente se apresenta como uma militante de grande importância para a cultura socialista e a luta das mulheres. Luxemburgo foi uma das principais lideranças fundadoras do Partido Comunista Alemão, defensora do socialismo. Nasceu em 05 de março de 1871, filha de judeus poloneses. Morreu assassinada em 15 de 
janeiro de 1919, durante a revolução alemã. Foi um exemplo de coragem. Como afirma Loureiro (2005), Luxemburgo “permanece até hoje uma figura fascinante tanto por suas idéias $[$ sic] políticas, quanto por sua coerência e integridade". Luxemburgo foi uma das militantes socialistas que empreendeu a luta contra "os preconceitos arraigados na socialdemocracia alemã, onde às mulheres eram reservados outros assuntos "femininos" (Loureiro, 2005, p.25). Lenin reconheceu a grandeza das contribuições de Rosa na luta contra o capitalismo. Exatamente por não se conformar com estas limitações buscou realizar "uma política partidária em pé de igualdade com os maiores teóricos do partido, não ficar numa posição subalterna" (Loureiro, 2005, p. 25), lutando contra toda forma de opressão social e individual. "Seu maior desejo sempre foi unir política e felicidade individual - desejo que cala no fundo do coração das mulheres". (idem, p. 26) o que é possível constatar em seus artigos e correspondências.

Luxemburgo (apud Loureiro, 2005, p.16) afirmou que: “O objetivo final do socialismo é o único elemento decisivo na distinção entre o socialista e o radical burguês". Essa distinção entre a visão de mundo burguesa, carregada de dominação e armadilhas para a consideração da condição da mulher, e a proposta de uma sociedade emancipatória, é o ponto de partida da luta de gênero, naquele momento e em nossos dias. Em um discurso em sua homenagem Lenin afirmou que, "[...] às vezes, as águias descem e voam entre as aves do quintal. Mas as aves do quintal jamais se elevarão até as nuvens". E continua... "Rosa equivocou-se em muitas coisas [...]. Mas, apesar de seus erros, foi para nós e continua sendo uma águia." (Loureiro, 2005, p. 22). Entre seus escritos destacamos especialmente as seguintes obras: "Introdução à economia política" (1925); “A acumulação do Capital” (1913); "Reforma ou Revolução" (1900).

Alexandra Kollontai, nascida em 1872, na Finlândia, país que fazia parte da Rússia czarista, é outra militante socialista que será destacada em nossos estudos. Entre seus escritos destacam-se: "A vida dos trabalhadores Finlandeses", publicado em 1903, seguido de "Através do Proletariado Europeu" e "A sociedade e a maternidade", publicados em 1905. Atendendo a uma solicitação de Lênin escreveu em 1915 “Quem quer a guerra?”; em 
1917 escreveu "Romance e Revolução"; publicou ainda "A mulher moderna e a classe trabalhadora", "Comunismo e Família", as novelas "Amor Vermelho", "Irmãs" e "O Amor de três gerações", além de "Carta a um jovem camarada". Entre suas obras destacam-se certamente "A nova mulher e a moral sexual" e "Autobiografia de uma mulher comunista sexualmente emancipada", que serão especialmente objeto de estudo e referências centrais em nossa pesquisa (Kollontai, A.,1979)

Esta destacada militante revolucionária russa apresenta-se como marco da luta pela condição social da mulher soviética. De família abastada, educada para a vida doméstica e o matrimônio, dedicou sua vida à classe trabalhadora e ao seu grande objetivo: "a libertação da Humanidade da opressão e da exploração pela via revolucionária” (Kollontai, A., p.7, 2007).

Em sua autobiografia Kollontai (2007, p.26) afirma a importância de sua luta e suas obras ao afirmar que:

[...] eu posso ser bem sucedida ao enfatizar aquilo que diz respeito à luta pela libertação das mulheres, e, além disso, o significado real que isso tem. Que eu não deveria moldar minha vida de acordo com um modelo preestabelecido, que teria que crescer além de mim mesma para ser capaz de discernir o meu verdadeiro ponto de vista, foi uma consciência que eu sempre tive desde a juventude. Ao mesmo tempo, também tive consciência que deste modo eu poderia ajudar minhas irmãs a moldar suas vidas, não conforme tradições dadas, mas com a própria opção livre, até o limite em que as circunstâncias sociais e econômicas permitam. Eu sempre acreditei que chegará o tempo em que uma mulher será julgada pelos mesmos padrões morais utilizados para os homens, pois não é a sua específica virtude feminina que lhe dá lugar de honra na sociedade humana, mas o valor da missão cumprida por ela, o valor de sua personalidade como ser humano, como membro da sociedade, como pensadora, como lutadora. Subconscientemente essa foi a força motriz das minhas ações.

É preciso destacar ainda, como a própria Kollontai (2007) relata em sua autobiografia, que ela conseguiu tornar-se membro do primeiro escalão do governo dos bolcheviques de 1917 a 1918, sendo a primeira mulher nomeada como embaixadora na História, fato que, segundo Kollontai, 
serviu para "provar que a mulher pode certamente elevar-se acima das condições convencionais da época". Ainda nos dias de hoje Kollontai destaca-se como uma das mais importantes figuras femininas dos séculos XIX e XX. E, na mesma linha, é possível pensar ainda hoje o preconceito de gênero numa perspectiva emancipatória a partir destes estudos. Os escritos da Ideologia Alemã (1846) apontam como a instituição da família provoca mudanças e dá origem à sociedade de classes, através de um processo que ocorre internamente no próprio processo da divisão do trabalho, como afirmam Marx e Engels (1970, p.47):

[...] a divisão do trabalho repousa sobre a divisão natural do trabalho na família e sobre a separação da sociedade em famílias isoladas e opostas umas às outras, - e esta divisão do trabalho implica ao mesmo tempo na repartição do trabalho e de seus produtos; distribuição desigual, na verdade, tanto em quantidade como em qualidade; ela implica pois na propriedade; assim, a primeira forma, o germe reside na família, onde a mulher e as crianças são escravas do homem. A escravidão, ainda latente e muito rudimentar na família, é a primeira propriedade.

No advento da sociedade capitalista houve e há uma repressão sobre o sexo, sobre o corpo, para sujeitá-lo em prol do trabalho alienado e o lucro. E o sexo é tão somente um dos instrumentos de repressão e dominação sobre a classe desfavorecida (o proletariado). Isso nos leva a pensar na problemática central do nosso estudo, que a partir dos fundamentos históricos e políticos da sexualidade feminina pretendemos esclarecer: - Historicamente, qual foi a contribuição das produções das mulheres socialistas, Alexandra Kollontai e Rosa Luxemburgo e o que essas concepções e reflexões oferecem para a análise, a crítica e a busca da superação da condição das mulheres na sociedade de classes, particularmente na sociedade capitalista? Que argumentos essas mulheres socialistas trouxeram para que se começasse a pensar sobre os preconceitos de gênero e consequentemente para a formação da consciência crítica e emancipatória de gênero?

Essas questões congregaram nossa motivação para o presente estudo. Todavia, em função da proposta de uma pesquisa de pós-doutoramento, 
logramos definir a recuperação da produção crítica e das análises de gênero efetuadas pelas mulheres socialistas como núcleo principal, de modo a basilar uma nova historiografia dos estudos sobre a condição da mulher. Não há, para nossa compreensão, como realizar estudos de gênero passando ao largo da produção e vivência das mulheres socialistas nominadas. Queremos recuperar esse movimento, suas produções e seus principais conceitos, bandeiras e propostas.

\section{Considerações iniciais}

O que se pode depreender é que, ao assumir hoje a recuperação do estado da arte sobre Sexualidade e Condição da Mulher, temos sempre uma historiografia de natureza burguesa, centrada numa linha sustentada sobre o conceito de indivíduo, pessoa, prazer, repressão, moral e poder, sempre relacionados à sexualidade. A consideração da dimensão social, a concepção da totalidade e de integralidade da condição humana não estão presentes nessas produções, a não ser como dados de bastidores ou contextos circunstanciais.Nossa pesquisa quer exatamente recuperar a originalidade da produção das mulheres e intelectuais orgânicas socialistas do período revolucionário russo. Estas mulheres protagonizaram uma interpretação peculiar, realizaram movimentos e críticas, teses e considerações políticas originais, que não encontram similaridades na tradição burguesa. Sobre esse filão esquecido queremos debruçar nossa atenção investigativa.

Podemos afirmar que, embora existam diversas fontes burguesas sobre a condição da mulher (a tradição sufragista, a luta das feministas de classe média no pós-guerra), dados e historiografia já disponíveis e também produções que nos ajudam a pensar a importância das produções marxistas para a superação dos preconceitos de gênero, acreditamos que há que se produzir outras contribuições que busquem ampliar o debate e preencher uma lacuna que há em muitas das produções que não consideram a relevância dos estudos socialistas para a superação das desigualdades sociais e sexuais ainda nos dias de hoje.

Consideramos que a superação da opressão da mulher só é possível após uma revolução social e, consequentemente, uma revolução sexual que 
fosse capaz de transformar os meios de produção e a riqueza produzida por eles, em propriedade social. Enquanto não eliminarmos a propriedade privada dos meios de produção, a exploração do homem pelo homem e não superarmos essa tradição patriarcal familiar, não conseguiremos nos libertar dessa opressão. Porém, temos consciência que a emancipação social e sexual da mulher é uma utopia e uma exigente tarefa política, pois a opressão da mulher está fundada numa tradição milenar. No mais, há que se esclarecer que liberdade não é fazer tudo que se tem vontade, nem diz respeito especificamente ao prazer e à orientação sexual como apregoam algumas feministas burguesas. Emancipar-se é adquirir a capacidade de pensar criticamente e agir de maneira ética. Ser livre exige consciência e responsabilidade em nossas escolhas e atos que devem ser pautados em valores éticos e estéticos.

A liberdade sexual burguesa, capitalista e mercantil, conduz a uma pseudoliberdade, a um processo de alienação e não de conscientização. Para sermos livres temos que ter antes de tudo consagrados direitos igualitários, no tocante à educação, a condições igualmente dignas de trabalho e salário, de emancipação econômica e de respeito às nossas potencialidades intelectuais, e consequentemente, à liberdade sexual, mas ressaltando que este não é o aspecto central, mas consequência da verdadeira emancipação que só é possível através da efetivação das questões anteriores, aquisição da consciência crítica e independência intelectual e financeira. A condição da emancipação da mulher não é uma causa das mulheres, e a raiz e motor da opressão não é o homem. Homens e mulheres são frutos das condições históricas, objetiva e politicamente condicionadas. E esta compreensão é possível através da leitura das obras das feministas Rosa Luxemburgo e Alexandra Kollontai que são objeto de estudo neste relatório de pesquisa de Pós-Doutoramento ainda em desenvolvimento.

\section{Referências}

ENGELS, F. A Origem da família, da propriedade privada e do Estado. Rio de Janeiro: Civilização Brasileira, 1974.

FRIGOTTO, G. Educação e a crise do capitalismo real. São Paulo: Cortez, 1995. 
FARIA, JR., A. G. Pesquisa em Educação Física: enfoques e paradigmas. In: FARIA JÚNIOR, A. G. ; FARINAT'TI, P. T. Pesquisa e produção de conhecimento em educação física. Rio de Janeiro: Ao Livro Técnico, 1992.

GUIMARÃES, Juarez R. (Org.). Rosa, a vermelha. São Paulo: Busca Vida, 1987, p. 166.

KOLLONTAI, A. Marxismo e Revolução Sexual. São Paulo: Global Editora, 1982.

KOLLONTAI, A. A nova mulher e a moral sexual. 3. ed. São Paulo: Global, 1979.

KOLLONTAI, A. Autobiografia de uma mulher emancipada. São Paulo:

Sundermann, 2007.

LOUREIRO, I. M. Rosa Luxemburgo: vida e obra. São Paulo: Expressão Popular, 2005.

LUXEMBURGO, R. Reforma Social on Revolução? 4. ed. São Paulo: Expressão Popular, 2005. [ a produção do conhecimento em educação: teorias e métodos]

LUXEMBURGO, R. Camarada e amante: cartas de Rosa Luxemburgo a Leo Jogiches. Rio de Janeiro: Paz e Terra, 1983.

LUXEMBURGO, R. A Revolução Russa. Petrópolis: Vozes, 1991.

MARX, K.; ENGELS, F. La Sagrada Familia. México: Grijalbo, 1967.

MARX, K.; ENGELS, F. L'idéologie allemande. Paris: Editions Sociales, 1970.

NUNES, C. A. Educarpara a Emancipação. Florianópolis, SC: Sophos, 2003.

MITCHELL, J. Woman's Estate.England: Penguin Books, 1971, p.99.

SÁNCHEZ GAMBOA, S. A. Epistemologia da Pesquisa em Educação: estruturas lógicas e tendências metodológicas. Tese (Doutorado em Educação).

Universidade Estadual de Campinas, Campinas, 1987. 